\title{
Scanning Electron Microscopy Investigation for Monitoring the Emulsion Deteriorative Process and Its Applications in Site-Directed Reaction with Paper Fabric
}

\author{
Liewei Qiu ${ }^{1,2}$, Yongkang Zhang ${ }^{1}$, Xueli Long ${ }^{3}$, Zhi Ye ${ }^{3}$, Zhangmingzu Qu ${ }^{1}$, Xiaowu Yang ${ }^{2}$ and Chen Wang ${ }^{2, *}$ \\ 1 Xi'an Key Laboratory of Textile Chemical Engineering Auxiliaries, School of Environmental and Chemical \\ Engineering, Xi'an Polytechnic University, Xi'an 710048, China; 20190607@xpu.edu.cn (L.Q.); \\ 41804010213@stu.xpu.edu.cn (Y.Z.); 42004010112@stu.xpu.edu.cn (Z.Q.) \\ 2 Key Laboratory of Auxiliary Chemistry and Technology for Chemical Industry, Ministry of Education, \\ Shaanxi Collaborative Innovation Center of Industrial Auxiliary Chemistry \& Technology, Shaanxi University \\ of Science and Technology, Xi'an 710021, China; yangxiaowu@sust.edu.cn \\ 3 Chemical Corporation of Changqing, Xi'an 710021, China; xuelilongcq@Petro-China.com.cn (X.L.); \\ yez0_cq@Petro-China.com.cn (Z.Y.) \\ * Correspondence: wangchenhg@sust.edu.cn; Tel./Fax: +86-029-86168830
}

check for updates

Citation: Qiu, L.; Zhang, Y.; Long, X.; Ye, Z.; Qu, Z.; Yang, X.; Wang, C. Scanning Electron Microscopy Investigation for Monitoring the Emulsion Deteriorative Process and Its Applications in Site-Directed Reaction with Paper Fabric. Molecules 2021, 26, 6471. https://doi.org/ $10.3390 /$ molecules 26216471

Academic Editors: Yujun Feng and Bruno Grassl

Received: 15 September 2021

Accepted: 25 October 2021

Published: 27 October 2021

Publisher's Note: MDPI stays neutral with regard to jurisdictional claims in published maps and institutional affiliations.

Copyright: (c) 2021 by the authors. Licensee MDPI, Basel, Switzerland. This article is an open access article distributed under the terms and conditions of the Creative Commons Attribution (CC BY) license (https:// creativecommons.org/licenses/by/ $4.0 /)$.

\begin{abstract}
The $\mathrm{O} / \mathrm{W}$ isocyanate emulsion can be used as a sizing agent to improve the waterproof performance of paper. However, the - $\mathrm{NCO}$ content in the emulsion diminishes with the prolongation of standing time. What is happening to this seemingly stable emulsion, especially concerning its microstructure evolution? We propose to monitor the emulsions deteriorative process by combining freeze-drying technique and SEM. Thus, the emulsion containing -NCO active group was obtained by the synthetic polymer emulsification of HDI trimers. The results of SEM demonstrate that the emulsion deteriorative process actually represents the collapsing and fusion of stable honeycomb structure with the prolongation of standing time and increasing temperature. This is possibly due to the fact that the inner aggregative HDI trimers are reacting with outside water to form urethane macromolecules, and this results in the collapsing and fusion of the honeycomb structure, as observed in SEM images. Moreover, the measurement results of -NCO content and FT-IR spectroscopy present the -NCO content as reducing with increasing standing time and temperature. This conclusion further proves our hypotheses. Additionally, the emulsions are used to treat the paper by sitedirected reaction. The results show that the with the increase of the standing time and temperature, the contact angles and surface free energy show a decrease and an increase, respectively, whereas surface free energy appeared at a minimum of $29.19 \mathrm{~mJ} \cdot \mathrm{m}^{-2}$ when the standing time and temperature was $1 \mathrm{~h}$ and $25^{\circ} \mathrm{C}$.
\end{abstract}

Keywords: morphological change; deteriorative monitoring; SEM investigation; site-directed reaction; sizing treatment

\section{Introduction}

Hexamethylene diisocyanate (HDI) trimers emulsions fall into category of active emulsions since they should have free isocyanate (-NCO) contents in the emulsion to react with non-woven fabrics and paper [1-3]. Since this reaction could convert the hydrogen bonding into chemical bonds between fibers [4], paper can become a new high-strength, water-resistant, oil-resistant special paper after the treatment. This work can open up broader prospects for the application of paper in packaging, printing, construction, and other industrial and agricultural production $[5,6]$.

The NCO groups can be so reactive that they react with almost all polar substances, so knowing the precise isocyanate content is important in aiding our evaluating of the quality of the materials. The reference test for the determination of NCO content is based on the modification of isocyanate functional groups to urea using dibuthyl amine solution 
in toluene followed by the titration of the excess dibuthyl amine with standardized hydrochloric acid solution. Other titration methods, such as using dicyclohexyl amine as an alternative to dibuthyl amine, have been developed [7-9]. However, there are a number of limitations. These methods are used for samples containing high isocyanate content. On the other hand, a large amount of sample is required when analyzing high molecular weight samples. Another limitation is that accurate titration cannot be performed in all solvents. Alternative methods for titration of simple isocyanates, such as using liquid chromatography, have been developed [10], but in many cases isocyanate the content of polymeric isocyanate cannot be determined by this method. FT-IR, middle infrared spectroscopy (MIR), and near infrared spectroscopy (NIR) has also been successfully utilized to determine NCO content of adhesive urethane prepolymers [11,12]. These methods have disadvantages such as poor accuracy of integration of peaks in infrared spectroscopy. Functional group analysis of polymers by NMR and ${ }^{19} \mathrm{~F}$ NMR spectroscopy is also known. Hydroxyl, amine, and acid functional groups of polymers have been successfully determined by ${ }^{19}$ F NMR spectroscopy [13-15]. The above-mentioned determination methods only emphasize on knowing the precise isocyanate content. The fact remains that we do not yet know the microstructure evolution caused by changes in isocyanate content. Therefore, to better understand the microstructure evolution process of emulsion with isocyanate content changes, we used freeze-drying and scanning electron microscopy to examine the microstructures evolution of isocyanate emulsion in different contents.

Given all this, the deteriorative process of the active emulsions is not still sufficiently studied and described in the literature. Therefore, the aim of the present work was to investigate the microstructure of active emulsions during their deteriorative processes with help of the combination of freeze-drying technique and SEM, which should be investigated in their original non-dried state [16] and allow us to obtain unique and valuable information about deteriorative process of the active emulsions.

\section{Materials and Methods}

\subsection{Materials}

Hexamethylene diisocyanate trimer, also named also known as 1,3,5-tris(6-iscoyanatohexyl) -1,3,5-triazine-2,4,6(1H,3H,5H)-trione, is a hexamethylene diisocyanate homopolymer. It was supplied by Kelude (Qingdao, China).

Copolymer P(OEGMA-co-HEMA-co-BMA) was prepared by ATRP polymerization reactions. The synthesis and characterization of the copolymer were presented in literature [17] and the structure of the copolymer P(OEGMA-co-HEMA-co-BMA) is shown in Figure 1 . The synthetic copolymer was used as an emulsifier to emulsify HDI trimer.

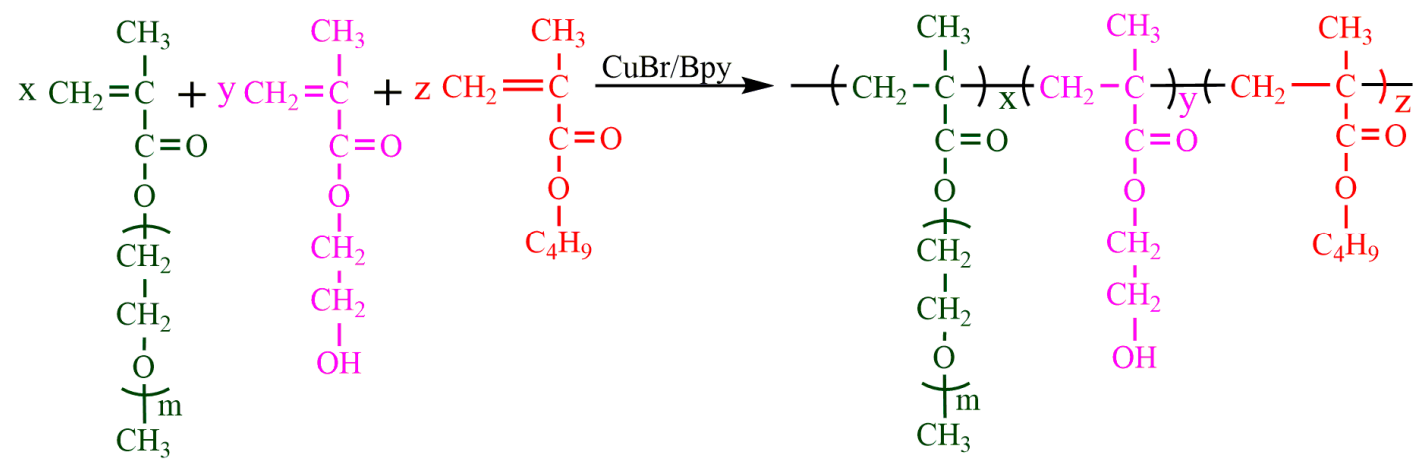

Figure 1. The structure of copolymer P(OEGMA-co-HEMA-co-BMA).

\subsection{Preparation of Micrometer Emulsion}

The N-Methyl pyrrolidone dissolved copolymer P(OEGMA-co-HEMA-co-BMA) prepared can be used as a macro-emulsifier to emulsify HDI trimer. The $1.0 \mathrm{~g}$ copolymer $\mathrm{P}(\mathrm{OEGMA-co-HEMA-co-BMA})$ and $5.0 \mathrm{~g}$ HDI trimer were added in a $100 \mathrm{~mL}$ dried 
three-necked flask, which was stirred at $60{ }^{\circ} \mathrm{C}$ for $1 \mathrm{~h}$ to make reaction between -OH in P(OEGMA-co-HEMA-co-BMA) with -NCO in HDI trimer. When the temperature approached to $25^{\circ} \mathrm{C}, 50.0 \mathrm{~g}$ water was added dropwise under stirring at $6000 \mathrm{r} / \mathrm{min}$ for $5 \mathrm{~min}$. Then, a stable $\mathrm{O} / \mathrm{W}$ emulsion was achieved.

\subsection{Characterization of Deteriorative Processes for Emulsion}

\subsection{1. -NCO Content Measurement}

The acetone-dibutylamine method was applied to test -NCO content. The sample (about $1.0000 \mathrm{~g}$ ) was transferred to an erlenmeyer flask and was dissolved with $15 \mathrm{~mL}$ acetone. $10 \mathrm{~mL}$ acetone-dibutylamine solution was added to the above solution, which was stirred $5 \mathrm{~min}$ at $25^{\circ} \mathrm{C}$. Then, a few drops of bromocresol green indicator was added, and $\mathrm{HCl}$ standard solution was used to titrate. The titration end-point reached to termination when the color of solution changed from green to yellow. In order to guarantee the accuracy of experimental data, three samples in the same test environment were measured. The blank experiment is carried out in the meantime. The -NCO content was calculated according to Equation (1).

$$
\mathrm{wt}_{(-\mathrm{CNO})}=\left(V_{0}-V_{1}\right) \times C \times 4.202 / \mathrm{m}
$$

where $C$ was the molar concentration of standard $\mathrm{NaOH}$ and $\mathrm{HCl}$ solutions, $m(\mathrm{~g})$ was the weight of sample taken, and $V_{0}$ and $V_{1}$ were the volume of $\mathrm{HCl}$ used for the titrating the excessive dibutylamine of blank and sample, respectively.

\subsubsection{SEM Investigation}

In order to monitor deteriorative processes of emulsion, the emulsions were drier using a freeze drier in liquid nitrogen in a vacuum environment. The dried emulsion samples were subjected to SEM using a scanning electron microscope (VEGA3, TESCAN, Brno, Czech Republic) to observe the microstructures of the emulsion. These samples were glued on an aluminum stub, and the surfaces were coated with gold.

\subsubsection{FT-IR Spectroscopy}

The deteriorative processes of emulsion were also monitored by FT-IR spectroscopy. The dried emulsion samples were ground into power to measure. The FT-IR spectroscopy of powers were recorded employing a Fourier transform infrared spectrophotometer (Model VERTEX70, Bruker, Karlsruhe, Germany) in the range of $4000-500 \mathrm{~cm}^{-1}$ as a potassium bromide pellet technique. The monitor of deteriorative processes was realized by the ratio of the integral area of isocyanate group $(-\mathrm{N}=\mathrm{C}=\mathrm{O})$ to the integral area of carbamate group $\left(-\mathrm{NH}-\mathrm{COO}^{-}\right)$.

\subsection{Characterization of Sizing-Treated Paper Fabric}

The untreated paper with a basis weight of about $80 \mathrm{~g} / \mathrm{m}^{2}$ was formed by cotton pulp. It $\left(5 \times 5 \mathrm{~cm}^{2}\right)$ was immersed in the sizing agent micrometer emulsion with a concentration of $50.0 \%$ for $10 \mathrm{~min}$, and then pressed between squeezing rolls to remove the excess liquid to reach about $95 \%$ wet pickup. Subsequently, the sizing-treated paper was dried at $105^{\circ} \mathrm{C}$ for $10 \mathrm{~min}$. The blank sample was made through the same treating procedure, except for using the deionized water instead of the micrometer emulsion. By comparing the change in quality of sizing before and after, the mass ratio of sizing agent to paper was $2.0 \%$.

\subsubsection{Dynamic Contact Angles}

The dynamic contact angle between distilled water and the surface of the sizingtreated paper fabric was measured at room temperature by a FIBRO 1100 DAT dynamic contact angle and penetrability analyzer (DCA, Stockholm, Sweden). The volume of the distilled water was $4 \mathrm{~mL}$ and the resistance was $18.5 \mathrm{M}$. The breadth of the samples was $15 \mathrm{~mm}$. 


\subsubsection{Surface Free Energy}

Contact angles are measured at $25^{\circ} \mathrm{C}$, and the results reported are the mean values of 5 replicates. The preferable equation to calculate the surface free energy, which is also surface free energy between polymers and an ordinary liquid, is as follows in Equation (2).

$$
\left(1+\cos \theta_{\text {liquid }}\right) \gamma_{\text {liquid }}=4\left(\frac{\gamma_{\text {liquid }}^{\mathrm{d}} \gamma^{\mathrm{d}}}{\gamma_{\text {liquid }}^{\mathrm{d}}+\gamma^{\mathrm{d}}}+\frac{\gamma_{\text {liquid }}^{\mathrm{p}} \gamma^{\mathrm{p}}}{\gamma_{\text {liquid }}^{\mathrm{p}}+\gamma^{\mathrm{p}}}\right)
$$

in which $\gamma=\gamma^{\mathrm{d}}+\gamma^{\mathrm{p}}, \gamma_{\text {liquid }}=\gamma_{\text {liquid }}^{\mathrm{d}}+\gamma_{\text {liquid }}^{\mathrm{p}} \gamma$ is the surface free energy, $\gamma^{\mathrm{d}}$ is the dispersion component, $\gamma^{\mathrm{p}}$ is polar component, $\theta_{\text {liquid }}$ is contact angle of the polymer with water or diiodomethane. The numerical values used are $\gamma_{\mathrm{H}_{2} \mathrm{O}}^{\mathrm{d}}=22.1 \mathrm{~mJ} / \mathrm{m}^{2}, \gamma_{\mathrm{H}_{2} \mathrm{O}}^{\mathrm{p}}=$ $50.7 \mathrm{~mJ} / \mathrm{m}^{2}, \gamma_{\mathrm{CH}_{2} \mathrm{I}_{2}}^{\mathrm{d}}=44.1 \mathrm{~mJ} / \mathrm{m}^{2}, \gamma_{\mathrm{CH}_{2} \mathrm{I}_{2}}^{\mathrm{p}}=6.70 \mathrm{~mJ} / \mathrm{m}^{2}$.

\section{Results and Discussion}

\subsection{Microstructure of Emulsion}

The copolymer P(OEGMA-co-HEMA-co-BMA) prepared can be used as an emulsifier to emulsify HDI trimers, which can be defined as a reactive macro-emulsifier. The $-\mathrm{OH}$ in HEMA can be reacted with HDI trimers and the water is added dropwise to achieve a stable $\mathrm{O} / \mathrm{W}$ emulsion. What's more, freeze-drying technique and SEM is combined to examine the exact microstructures of emulsion. Seen from Figure 2, the emulsion exhibits honeycomb structures. The reason about formation of this kind of structure is that the reactive macro-emulsifier divides the emulsion into two stable phases. One is the outer water phase with extended OEGMA segment and the other is inner aggregation areas of HDI trimers and organic solvents. As freeze-drying technique is used to remove the water, the lightweight polymer skeleton is formed. Moreover, the process of freeze-drying also removes the HDI trimers and organic solvents, which is the reason for the formation of the cellular honeycomb structures. The schematic diagram of the honeycomb structure is depicted in Figure 3.
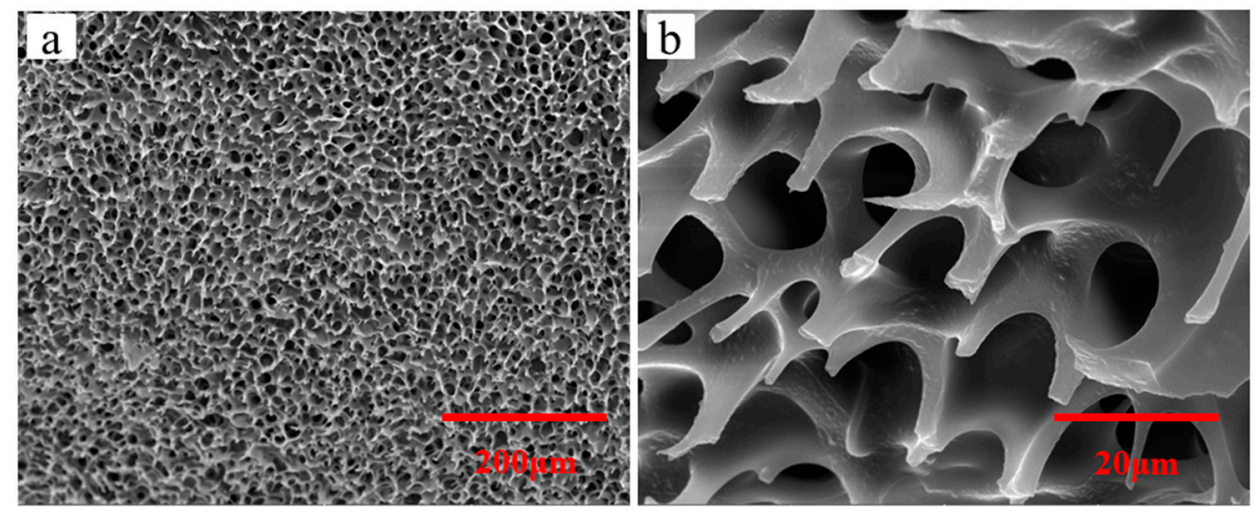

Figure 2. Micrograph of emulsion at (a) low- and (b) high-magnification. 


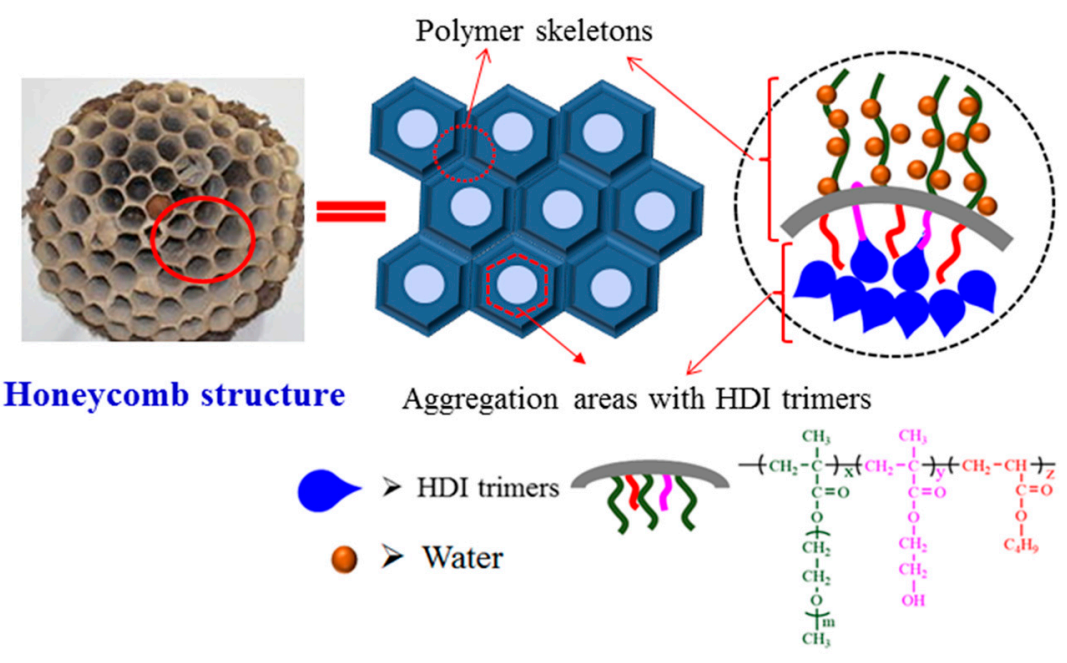

Figure 3. Schematic diagram of the honeycomb structure.

\subsection{Effect of Time on Deteriorative Processes of Emulsion}

\subsection{1. -NCO Content and SEM Investigation}

Detecting the $-\mathrm{NCO}$ content in the emulsions is a common method to investigate whether the emulsion undergoes deterioration. Seen from the digital photos in Figure 4, the appearance of emulsion does not change over time. However, the -NCO content is decreased obviously in the emulsion with the increase of storage time. It means that the emulsion has already loses its activity and becomes inactivated despite the unchanged appearance of the emulsion.

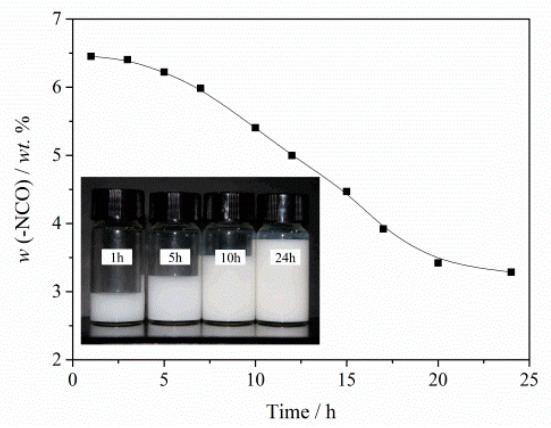

Figure 4. -NCO content in the emulsions via different standing time and their digital photos.

What is happened in the seemingly stable emulsion? SEM investigation is a novel and exact method to observe the deterioration of emulsion virtually. Micrographs of emulsions via different standing time are shown in Figure 5. The exact microstructure of emulsion with $1 \mathrm{~h}$ standing time (Figure 5a) basically maintains the original honeycomb structures as shown in Figure 2, which indicates that the emulsion remains its activity. With increase of the time, the honeycomb structures are collapsed and the holes are fused. (Figure $5 \mathrm{~b}-\mathrm{d}$ ). The possible reason is that copolymer $\mathrm{P}(\mathrm{OEGMA-Co-HEMA-co-BMA)}$ can be only a temporary physical skeleton to divided the emulsion into two phases and they will be partly fused due to molecular kinetic theory. Moreover, HDI trimers has active-NCO groups, which can be reacted with water as they are contacted. With the increase of standing time, more and more -NCO groups are reacted with outside water to form carbamates macromolecules and only the unreacted HDI trimers and organic solvents are removed to form random holes in the process of freeze-drying. Therefore, the honeycomb structures disappeared over standing time of emulsion and the emulsions with no honeycomb structures can be defined as inactivated emulsion or deteriorative emulsion. The deteriorative processes of emulsions can be interpreted in Figure 6. 

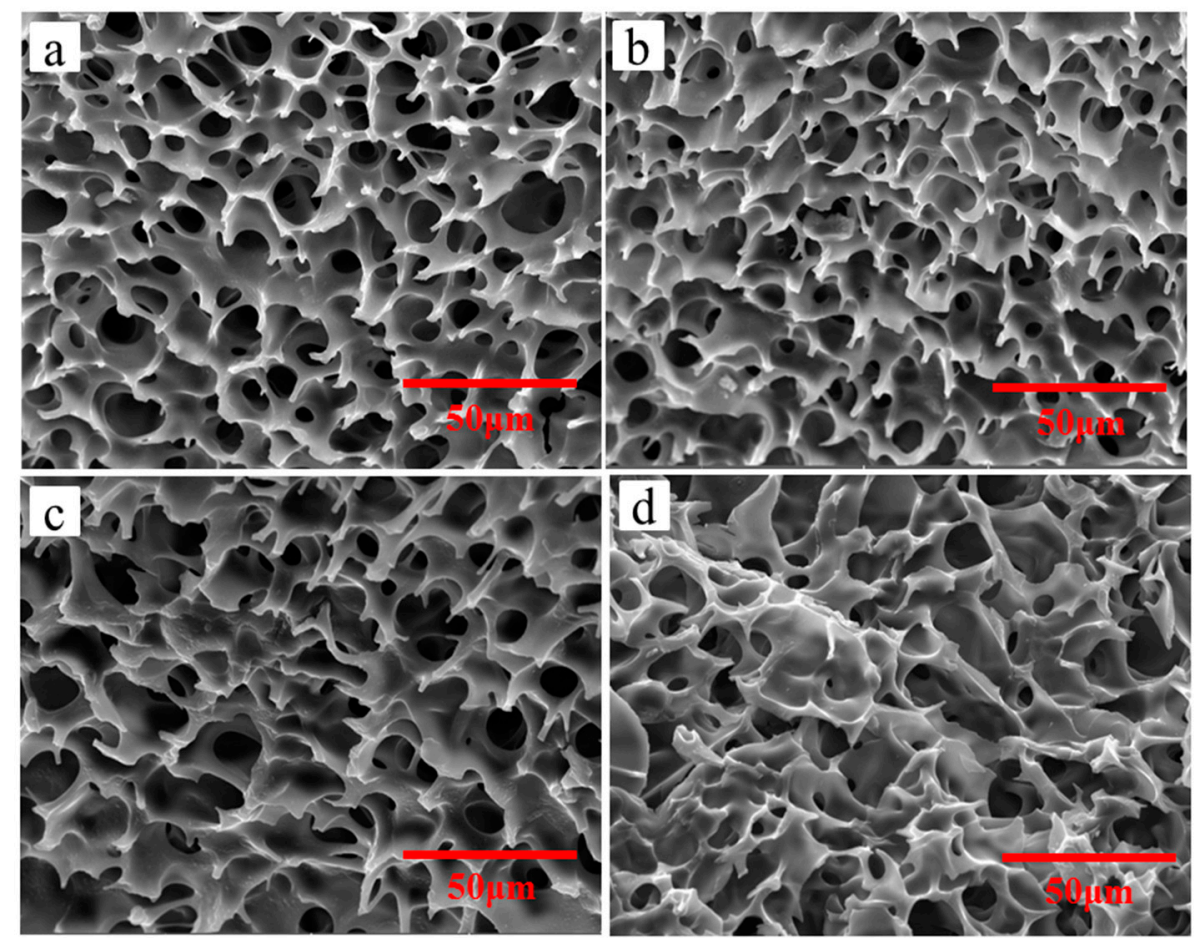

Figure 5. Micrograph of emulsions via different standing time: (a) 1 h; (b) 5 h; (c) 10 h; and (d) 24 h.

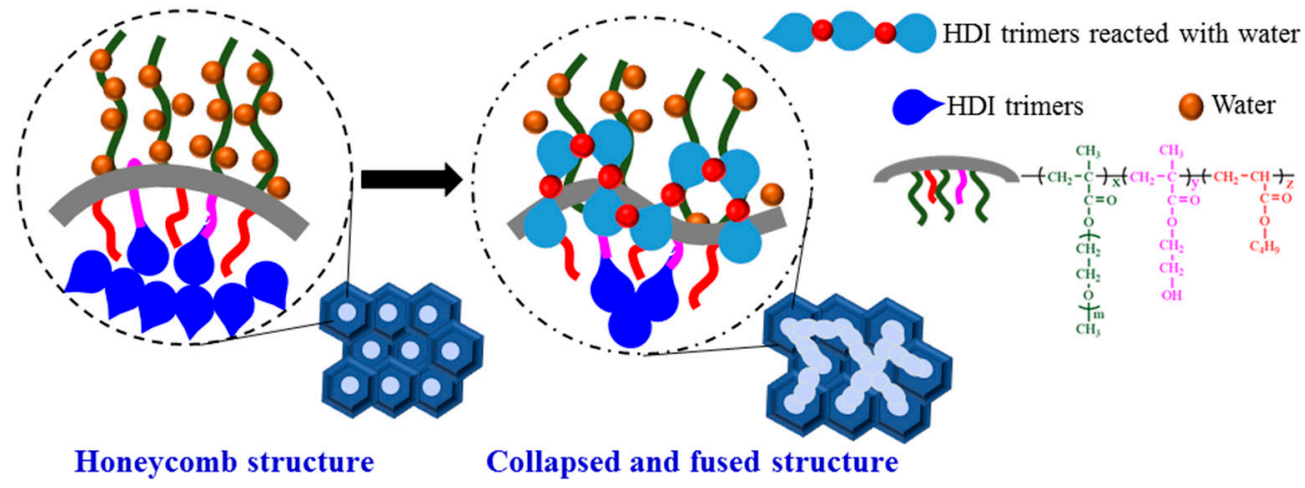

Figure 6. Schematic process of the collapsing and fusion of honeycomb structure.

\subsubsection{FT-IR Spectroscopy}

Based on the discovery for the changing micrograph of emulsions, the FT-IR spectroscopy in Figure 7 and data in Table 1 confirms these results. Carbamate (-NH) groups and isocyanate $(-\mathrm{N}=\mathrm{C}=\mathrm{O})$ groups appear in near 3500 and $2250 \mathrm{~cm}^{-1}$, respectively. Due to the reaction of HDI trimers with water, there will be more $-\mathrm{NH}$ groups and less $-\mathrm{N}=\mathrm{C}=\mathrm{O}$ groups in the system. With the increase of standing time, the peaks of - $\mathrm{NH}$ groups become wider and their values of integral area increase. To the contrary, the peaks of $-\mathrm{N}=\mathrm{C}=\mathrm{O}$ groups become smaller and narrower, and their values of integral area decrease appaerently. At this time, we difine the ratio of $-\mathrm{NH}$ groups integral area to $-\mathrm{N}=\mathrm{C}=\mathrm{O}$ groups integral area as $\mathrm{S}_{(-\mathrm{NH})}: \mathrm{S}_{(-\mathrm{N}=\mathrm{C}=\mathrm{O})}$. Seen from Table 1 , the value of $\mathrm{S}_{(-\mathrm{NH})}: \mathrm{S}_{(-\mathrm{N}=\mathrm{C}=\mathrm{O})}$ increases from 1.219 to 5.207 when the standing time of emulsion changes from $1 \mathrm{~h}$ to $24 \mathrm{~h}$. All the FT-IR data confims that more and more-NCO groups are reacted with outside water to form carbamates macromolecules with the increase of standing time of emulsion, which coincides with explanation of collapsing and fused of honeycomb structures. 


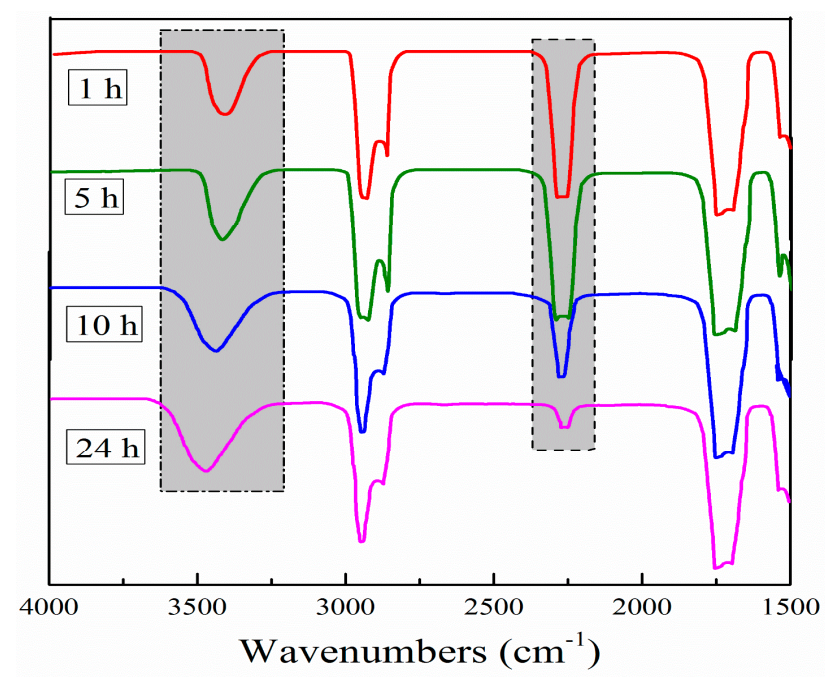

Figure 7. FT-IR spectra of emulsion with different standing time.

Table 1. Integral area of carbamate groups $(-\mathrm{NH})$ and isocyanate groups $(-\mathrm{N}=\mathrm{C}=\mathrm{O})$ of emulsions with different standing time in FT-IR spectra.

\begin{tabular}{cccc}
\hline Samples & $\mathbf{S}_{(-\mathrm{NH})}$ & $\mathbf{S}_{(-\mathrm{N}=\mathrm{C}=\mathbf{O})}$ & $\mathbf{S}_{(-\mathrm{NH})}: \mathbf{S}_{(-\mathrm{N}=\mathrm{C}=\mathbf{O})}$ \\
\hline $1 \mathrm{~h}$ & 239.81 & 199.89 & 1.219 \\
$5 \mathrm{~h}$ & 243.16 & 196.84 & 1.235 \\
$10 \mathrm{~h}$ & 307.01 & 133.21 & 2.305 \\
$24 \mathrm{~h}$ & 369.02 & 70.87 & 5.207 \\
\hline
\end{tabular}

\subsection{Effect of Temperature on Deteriorative Processes of Emulsion}

\subsection{1. -NCO Content and SEM Investigation}

The temperature is also an important factor for deterioration of emulsions. We heated the emulsion to different temperature for $10 \mathrm{~min}$ and restore the $-\mathrm{NCO}$ content at room temperature. When the temperature is from room temperature to $50^{\circ} \mathrm{C}$, the appearances of emulsions present stable state (digital photos in Figure 8), and the -NCO content decrease slightly (Figure 8). However, when the temperature is above $50{ }^{\circ} \mathrm{C}$, the $-\mathrm{NCO}$ content decrease dramatically. As shown in the digital photos in Figure 8, the appearances of emulsions show separated phases when the temperature reaches to $70{ }^{\circ} \mathrm{C}$ and $90{ }^{\circ} \mathrm{C}$. However, their appearances change to viscous and stable phases when the temperatures are cooling to $25^{\circ} \mathrm{C}$. Therefore, it is impossible to judge the degree of emulsion deterioration from the appearance alone when emulsion suffers from short time heat.

Herein, SEM is used to investigate the exact structure of emulsions after suffering from short time heat. Figure 9 shows micrographs of emulsions suffering from $10 \mathrm{~min}$ heat via different temperature, which are tested using the samples at room temperature and corresponds to the digital photos in Figure 8. Although all of the appearances of testing samples are stable and no separation, the exact structure of the emulsion has already changed dramatically. At room temperature, the emulsion shows honeycomb structures (Figure 9a) which is depicted in Figure 3. Moreover, the stable honeycomb structures have done little damage when the emulsion suffers from 10 min heat with $50{ }^{\circ} \mathrm{C}$ (Figure $9 \mathrm{~b}$ ), which demonstrates that the emulsion do not deteriorate at this time. However, when the emulsion suffers from $10 \mathrm{~min}$ heat with $70^{\circ} \mathrm{C}$ (Figure 9c), especially at $90^{\circ} \mathrm{C}$ (Figure 9d), the honeycomb structures have collapsed and fused. The results are consistent with the data of existed -NCO content. The possible reason is that copolymer P(OEGMA-co-HEMA-coBMA) can be only a temporary physical skeleton to divided the emulsion into two phases. With an increase of the treating temperature for emulsions, more and more -NCO groups is reacted with outside water to form carbamates macromolecules and the unreacted HDI trimers and organic solvents are removed to form random fused holes in the process of 
freeze-drying. Therefore, the honeycomb structures disappeared. Emulsions with strongly damaged honeycomb structures can be defined as inactivated emulsion or deteriorative emulsion. The deteriorative processes of emulsions can be interpreted in Figure 6.

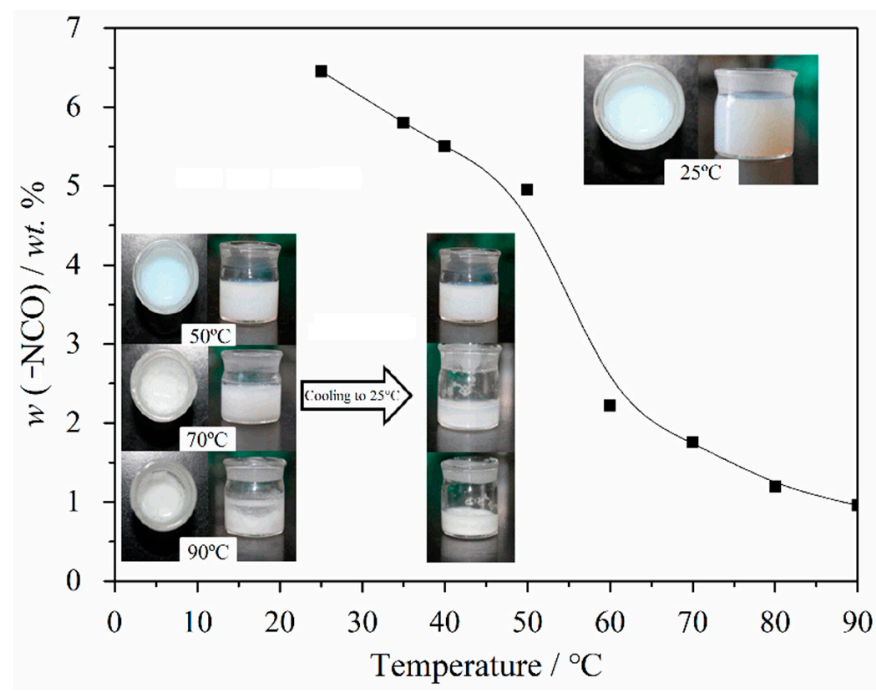

Figure 8. - $\mathrm{NCO}$ content in the emulsions suffering from 10 min heat via different temperature and their digital photos.
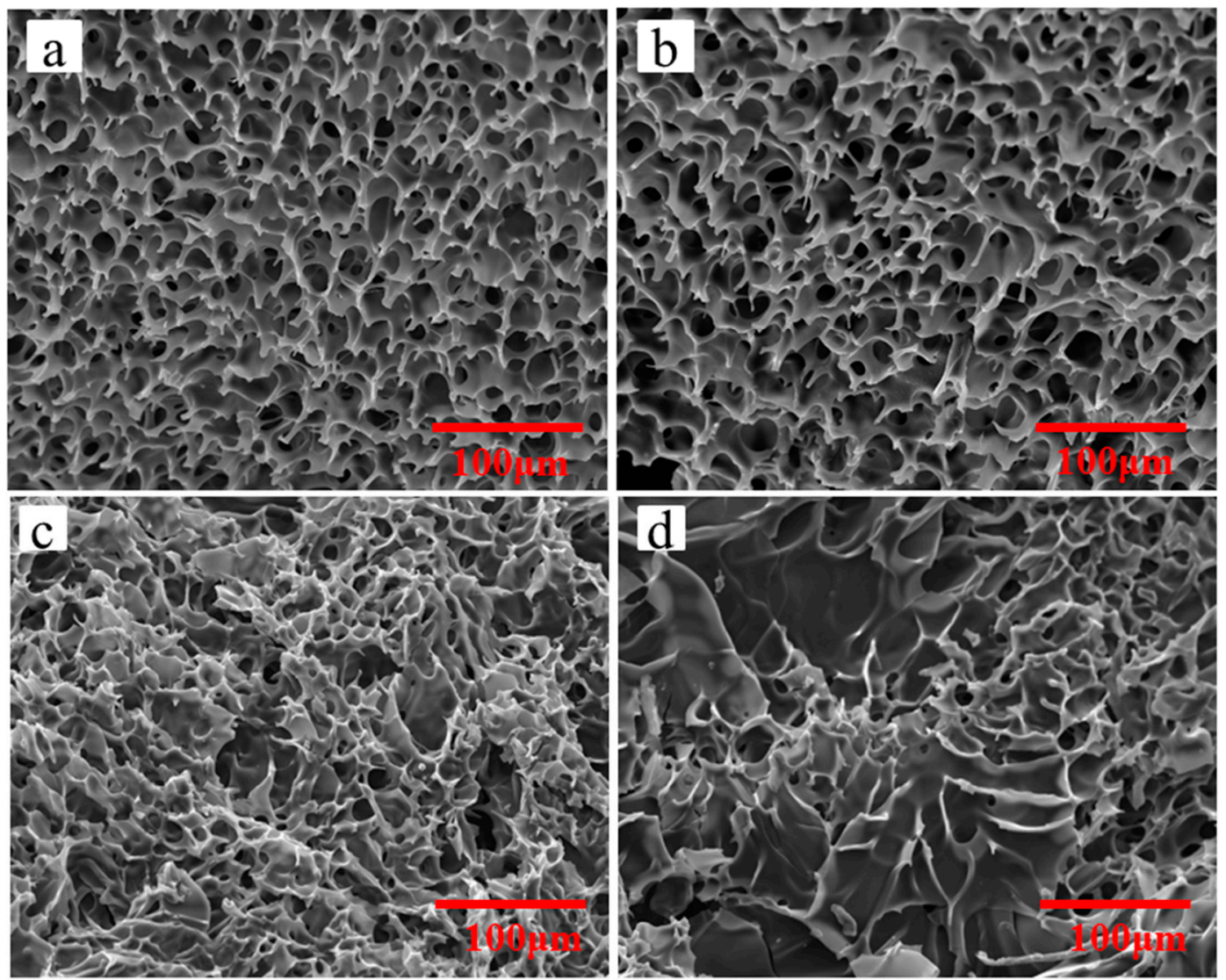

Figure 9. Micrograph of emulsions suffering from $10 \mathrm{~min}$ heat via different temperature: (a) $25^{\circ} \mathrm{C}$; (b) $50^{\circ} \mathrm{C}$; (c) $70{ }^{\circ} \mathrm{C}$; and (d) $90^{\circ} \mathrm{C}$. 


\subsubsection{FT-IR Spectroscopy}

Like the analysis of FT-IR spectroscopy in Section 3.2.2, Table 2 shows integral areas of carbamate groups and isocyanate groups of emulsions in the FT-IR spectra, which suffer from 10 min heat via different temperature. Due to the reaction of HDI trimers with water, there will be more $-\mathrm{NH}$ groups and less $-\mathrm{N}=\mathrm{C}=\mathrm{O}$ groups in the system. With the increase of treating temperature, the values of integral areas (-NH groups) increase. On the contrary, the values of integral areas $(-\mathrm{N}=\mathrm{C}=\mathrm{O}$ groups) decrease correspondingly. The value of $\mathrm{S}_{(-\mathrm{NH})}: \mathrm{S}_{(-\mathrm{N}=\mathrm{C}=\mathrm{O})}$ increases from 1.219 to 2.715 and does not increase so much as when the treating temperature of emulsion increases from room temperature to $50{ }^{\circ} \mathrm{C}$. Combined with results of SEM, the exact emulsion microstructures have largely kept the honeycomb structures, depicting that the emulsion should be highly active at this time. However, when the treating temperature of emulsion increaes from $50{ }^{\circ} \mathrm{C}$ to $70{ }^{\circ} \mathrm{C}$, then to $90^{\circ} \mathrm{C}$, the value of $\mathrm{S}_{(-\mathrm{NH})}: \mathrm{S}_{(-\mathrm{N}=\mathrm{C}=\mathrm{O})}$ increases dramatically to 4.043 and 8.603 , respectively, showing that more and more -NCO groups are reacted with outside water to form carbamates macromolecules. This coincides with explanation of collapsing and fused of honeycomb structures.

Table 2. Integral area of carbamate groups $(-\mathrm{NH})$ and isocyanate groups $(-\mathrm{N}=\mathrm{C}=\mathrm{O})$ of emulsions suffering from 10min heat via different temperature in FT-IR spectra.

\begin{tabular}{cccc}
\hline Samples & $\mathbf{S}_{(-\mathrm{NH})}$ & $\mathbf{S}_{(-\mathrm{N}=\mathrm{C}=\mathbf{O})}$ & $\mathbf{S}_{(-\mathrm{NH})}: \mathbf{S}_{(-\mathrm{N}=\mathrm{C}=\mathbf{O})}$ \\
\hline $25^{\circ} \mathrm{C}$ & 239.81 & 199.89 & 1.219 \\
$50^{\circ} \mathrm{C}$ & 315.23 & 116.68 & 2.715 \\
$70^{\circ} \mathrm{C}$ & 353.79 & 87.59 & 4.043 \\
$90^{\circ} \mathrm{C}$ & 394.63 & 45.87 & 8.603 \\
\hline
\end{tabular}

\subsection{The Site-Directed Reaction of Active Substances with Paper Fibers}

As shown in Figure 10, the hydroxyl groups between the paper sheets are hydrogenbonded, and the hydrogen bonding is not only low in bond energy but also easily destroyed by water molecules, showing that the wet strength of plain paper is relatively low. On the other hand, after the emulsion-treated paper, the hydroxyl groups between the fibers reacted with -NCO to convert hydrogen bonds into chemical bonds, which enhanced the strength of the paper and overcome the shortcomings of traditional paper strength is not high.

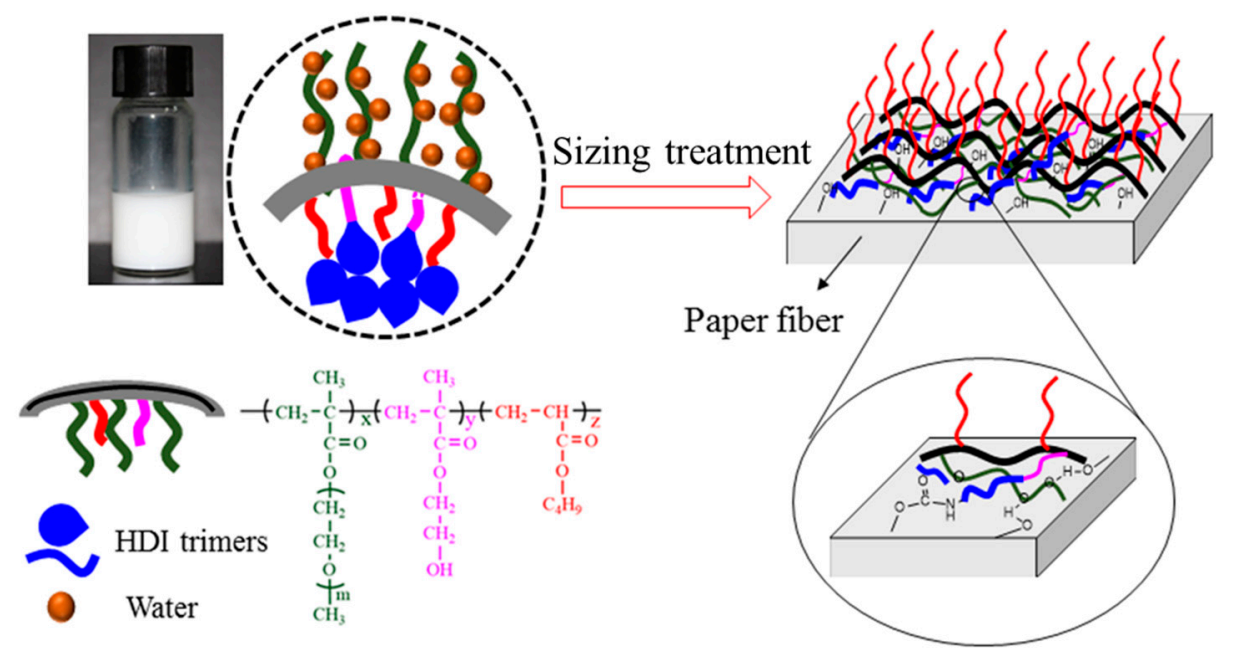

Figure 10. Schematic diagram of site-directed reaction of active material and paper fiber.

\subsubsection{Dynamic Contact Angles}

Compared with the blank sample, the contact angle of the emulsion significantly increased as shown in Figure 11. For example, the contact angle of a blank sample is 
quickly decreases from $92.5^{\circ}$ (in $0.2 \mathrm{~s}$ ) to $0^{\circ}$ (in $4.8 \mathrm{~s}$ ). When left at $25^{\circ} \mathrm{C}$ for $1 \mathrm{~h}$, the hydrophobic segments can form a hydrophobic film on the fiber surface and change the morphology of the fiber surface, so the sample shows excellent hydrophobicity. As the residence time and temperature of the emulsion increase, more and more -NCO groups react with external water to form urethane macromolecules, resulting in a decrease in the activity of the emulsion (compare with the SEM image of Figure 9). When the temperature rises to $70{ }^{\circ} \mathrm{C}$ and then drop to $25^{\circ} \mathrm{C}$, and the contact angle of the emulsion does not change. Since the reaction of -NCO groups with external water to form urethane macromolecules is an irreversible reaction, the emulsion after high temperature has been changed, so the contact angle does not increase after a significant decline.

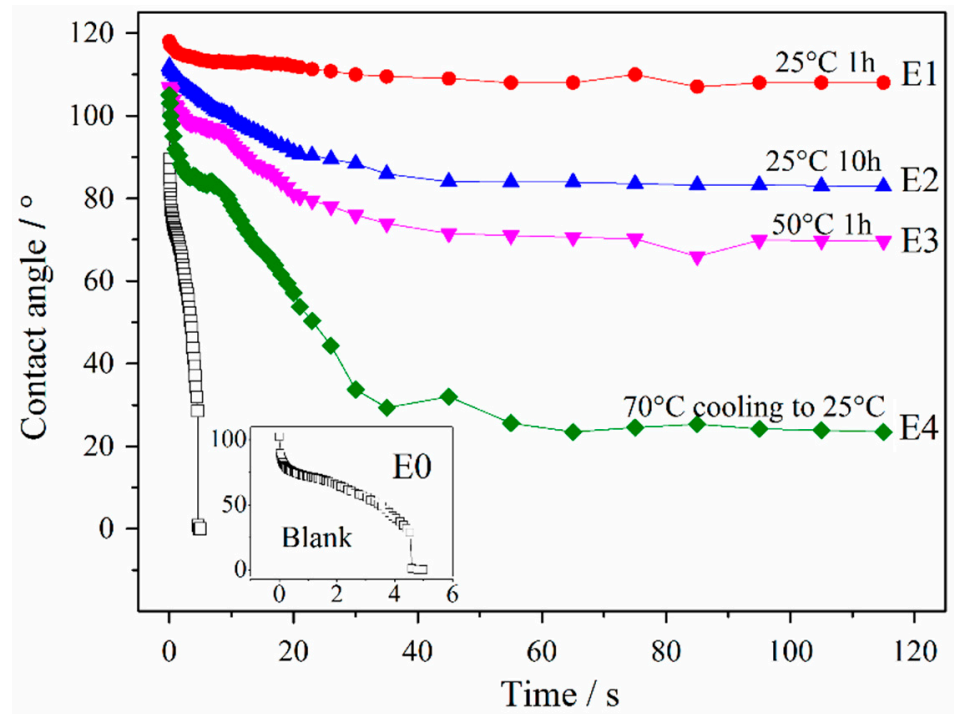

Figure 11. The dynamic contact angle of the sizing-treated paper fabric with different emulsions.

\subsubsection{Surface Free Energy}

Table 3 shows the surface free energy (calculated by the contact angle with water and diiodomethane) of sized paper fabrics of different emulsions. The coating surface has a higher $\gamma^{\mathrm{d}}$ and a smaller $\gamma^{\mathrm{p}}$, indicating that there is a large contact angle between the polar liquid and the non-polar coating film. At the same time, the surface free energy increased from $29.19 \mathrm{~mJ} \cdot \mathrm{m}^{-2}$ to $38.81 \mathrm{~mJ} \cdot \mathrm{m}^{-2}$. The surface free energy of the film is increased by $32.96 \%$. The reason for these apparent changes may involve increasing the number of hydrophilic units in the copolymer [18]. The results show that as the temperature and time for the emulsion increase, more and more - $\mathrm{NCO}$ groups react with external water to form urethane macromolecules, which destroys the structure of the emulsion and decreases the water resistance.

Table 3. Surface free energy of the sizing-treated paper fabric with different emulsions.

\begin{tabular}{|c|c|c|c|c|c|}
\hline \multirow{2}{*}{ Emulsion Sample } & \multicolumn{2}{|c|}{ Contact Angles $/^{\circ}$} & \multicolumn{3}{|c|}{ Surface Free Energy $/\left(\mathrm{mJ} \cdot \mathrm{m}^{-2}\right)$} \\
\hline & Water & Diiodomethane & $\gamma^{\mathbf{d}}$ & $\gamma^{p}$ & $\gamma$ \\
\hline E1 & & & 27.10 & 2.09 & 29.19 \\
\hline E2 & & & 28.10 & 3.14 & 31.24 \\
\hline E3 & & 47.3 & 29.89 & 4.29 & 34.18 \\
\hline E4 & 3 & $=30.1$ & 34.40 & 4.41 & 38.81 \\
\hline
\end{tabular}




\section{Conclusions}

The emulsion containing - NCO active group was obtained by the emulsification of Hexamethylene diisocyanate (HDI) trimers, and it can be used as a sizing agent to improve the waterproof performance of paper. However, the -NCO content is diminishing with the prolongation of standing time and increasing temperature. What is happened to this seemingly stable emulsion especially microstructure evolution? Herein, we combined freeze-drying technique and SEM to monitoring the emulsions' deteriorative process. The results demonstrate that the deteriorative process is actually the collapsing and fusion of stable honeycomb structure with the prolongation of standing time and increasing temperature. This is possibly due to the fact that the inner aggregation HDI trimmers are reacted with outside water to form urethane macromolecules, and result in collapsing and fusion of honeycomb structure, as observed in SEM images. Moreover, the measurement results of -NCO content and FT-IR spectroscopy present the -NCO content is reducing with increasing standing time and temperature. This method of combining freeze-drying technique and SEM may be useful tool to monitor and study microstructure evolution and may be important in aiding our understanding of the mechanism of chemical processes. In addition, the stable emulsions are used to treat the paper by site-directed reaction. The results show that the with the increase of the standing time and temperature, the contact angles and surface free energy show a decrease and an increase, respectively, whereas surface free energy appeared a minimum $29.19 \mathrm{~mJ} \cdot \mathrm{m}^{-2}$ when the standing time and temperature was $1 \mathrm{~h}$ and $25^{\circ} \mathrm{C}$.

Author Contributions: Conceptualization, L.Q. and Y.Z.; methodology, Y.Z. and Z.Q.; validation, L.Q. and C.W.; investigation, X.L. and Z.Y.; data curation, L.Q.; writing-original draft preparation, L.Q. and C.W.; writing - review and editing, L.Q.; project administration, X.Y.; funding acquisition, L.Q. and C.W. All authors have read and agreed to the published version of the manuscript.

Funding: This research was funded by the Natural Science Basic Research Program of Shaanxi Province, 2021JQ-669; Science and Technology Projects of Xi'an City, 20193053YF041NS041; Scientific Research Projects of Xi'an Polytechnic University, 107020557.

Institutional Review Board Statement: Not applicable.

Informed Consent Statement: Not applicable.

Data Availability Statement: The data presented in this study are available from the authors.

Acknowledgments: We would like to acknowledge financial support from the Natural Science Basic Research Program of Shaanxi Province, the Science and Technology Projects of Xi'an City, the Scientific Research Projects of Xi'an Polytechnic University and College Students' Innovative Training Plan Program of Xi'an Polytechnic University.

Conflicts of Interest: The authors declare no conflict of interest.

Sample Availability: Samples of the compounds are available from the authors upon request.

\section{References}

1. Decostanzi, M.; Auvergne, R.; Darroman, E.; Boutevin, B.; Caillol, S. Reactivity and kinetics of HDI-iminooxadiazinedione: Application to polyurethane synthesis. Eur. Polym. J. 2017, 96, 443-451. [CrossRef]

2. Libni, G.; Nasar, A.S. Catalysis of Forward and Reverse Reactions of epsilon-Caprolactam-Blocked Polyisocyanate: Double Arrhenius Plots and Equilibrium Temperatures of a Thermally Reversible Reaction. ChemistrySelect 2017, 2, 9586-9594. [CrossRef]

3. Poljanšek, I.; Fabjan, E.; Moderc, D.; Kukanja, D. The effect of free isocyanate content on properties of one component urethane adhesive. Int. J. Adhes. 2014, 51, 87-94. [CrossRef]

4. Li, A.; Fan, G.; Chen, H.; Zhao, Q. Synthesis and characterization of water-borne diisocyanate crosslinkers from methyl ethyl ketoxime/2-methylimidazole-blocked aromatic isocyanates. Res. Chem. Intermediat. 2013, 39, 3565-3577. [CrossRef]

5. Guo, L.; Wang, L.; Huang, S.; Qu, J. Synthesis and properties of novel water-dispersible polyisocyanates. J. Appl. Polym. Sci. 2017, 134, 44735. [CrossRef]

6. Lou, C.; Di, M. Study on cross-linking agent of a novel one-component API adhesive. J. Adhes. Sci. Technol. 2013, 27, 2340-2351. [CrossRef] 
7. Ma, G.; Guan, T.; Hou, C.; Wu, J.; Wang, G.; Ji, X.; Wang, B. Preparation, properties and application of waterborne hydroxylfunctional polyurethane/acrylic emulsions in two-component coatings. J. Coat. Technol. Res. 2015, 12, 505-3512. [CrossRef]

8. Ji, W.; Song, W.; Zheng, Y.; He, X. Improvement of method for determination of isocyanate group content in polyurethane prepolymer. Appl. Mech. Mater. 2013, 303, 2533-2536. [CrossRef]

9. Lai, X.; Shen, Y.; Wang, L.; Li, Z. Preparation and performance of waterborne polyurethane/nanosilica hybrid materials. Polym.-Plast. Technol. 2011, 50, 740-747. [CrossRef]

10. Marand, A.; Dahlin, J.; Karlsson, D.; Skarping, G.; Dalene, M. Determination of technical grade isocyanates used in the production of polyurethane plastics. J. Environ. Monit. 2004, 6, 606-614. [CrossRef] [PubMed]

11. Modesti, M.; Lorenzetti, A. An experimental method for evaluating isocyanate conversion and trimer formation in polyisocyanatepolyurethane foams. Eur. Polym. J. 2001, 37, 949-954. [CrossRef]

12. Zhang, Y.; Maxted, J.; Barber, A.; Lowe, C.; Smith, R. The durability of clear polyurethane coil coatings studied by FTIR peak fitting. Polym. Degrad. Stabil. 2013, 98, 527-534. [CrossRef]

13. Ma, Y.; Agarwal, U.; Vekemans, J.; Sikkema, J. NMR based determination of minute acid functionality: End-groups in PET. Polymer 2003, 44, 4429-4434. [CrossRef]

14. Moghimi, A.; Omrani, I.; Khanmiri, H.R.; Bahadorbeigi, R.; Mahmoodi, M. Determination of NCO content of the urethane prepolymers by ${ }^{19}$ F NMR spectroscopy. Polym. Test. 2014, 33, 30-33. [CrossRef]

15. Ji, S.; Hoye, R.T.; Macosko, c. Primary amine quantification in Polymers: Functionality by ${ }^{19}$ F NMR Spectroscopy. Macromolecules 2005, 38, 4679-4686. [CrossRef]

16. Qiu, L.; Shen, Y.; Wang, C.; Yang, X. Scanning electron microscopy analysis of guar gum in the dissolution, gelation and gel-breaking process. Polym. Test. 2018, 68, 95-99. [CrossRef]

17. Jiang, B.; Zhang, L.; Liao, B.; Pang, H. Self-assembly of well-defined thermo-responsive fluoropolymer and its application in tunable wettability surface. Polymer 2014, 55, 5350-5357. [CrossRef]

18. Bayer, S.; Brandi, F.; Cingolani, R.; Athanassiou, A. Modification of wetting properties of laser-textured surfaces by depositing triboelectrically charged Teflon particles. Colloid Polym. Sci. 2013, 291, 367-373. [CrossRef] 